\title{
Análise da variação de temperaturas em telhas revestidas com manta impermeabilizante de PVC
}

Superficial temperature analysis on roof tiles coated with PVC waterproofing membrane

Análisis de la variación de temperatura en baldosas revestidas con manta impermeable de PVC

\section{Resumo}

A busca por ambientes construídos com melhor climatização para o usuário é um interesse crescente na construção civil, além de garantir um ambiente com estanqueidade, sem infiltrações e poder proporcionar ambientes com temperaturas mais amenas. Neste sentido, o objetivo deste trabalho foi avaliar se a utilização de manta impermeabilizante de PVC melhora o conforto térmico em edificações. Os ensaios foram realizados em laboratório e em campo, avaliando a variação de temperatura nas faces opostas de telhas com e sem revestimento em manta impermeabilizante de PVC. Em laboratório as temperaturas superficiais foram avaliadas sob a incidência de luz de um refletor. Em campo, fez-se a medição sobre incidência direta do sol. Os resultados permitiram concluir que a manta não atua somente como impermeabilizante, mas como refletor da radiação solar, proporcionando uma diferença entre a temperatura externa e interna na telha de até $20^{\circ} \mathrm{C}$. O uso de mantas impermeabilizantes de PVC para a melhora térmica em edificações é efetivo, acarretando reflexão de parte da radiação solar incidente sobre a superfície de cobertura da edificação, dificultando a passagem de calor para a área interna.

Palavras-chave: Telhas; Manta PVC; Avaliação Térmica.

\begin{abstract}
The search for built environments with better air conditioning for the user is a growing interest in civil construction, in addition to guaranteeing a watertight environment, without infiltration and being able to provide environments with milder temperatures. In this sense, the objective of this work was to evaluate whether the use of waterproofing PVC coating improves thermal comfort in buildings. The tests were carried out at laboratory and field conditions, evaluating the temperature variation on the faces of tiles with and without waterproofing PVC coating. In the laboratory, surface temperatures were evaluated under the incidence of light from a reflector. In the field, direct sunlight was measured. The results showed that the use of PVC coating acts as a waterproofing agent, and as reflector of solar radiation, providing a difference between the external and internal temperature in the tile of about $20^{\circ} \mathrm{C}$. The use of waterproofing PVC coating for thermal improvement in buildings is effective, resulting in the reflection of part of the solar radiation incident on the covering surface of buildings, hindering the passage of heat to the internal area.
\end{abstract}

Keywords: Tiles; PVC coating; Thermal evalutation.

\section{Resumen}

La búsqueda de ambientes construidos con mejor climatización para el usuario es un interés creciente por la construcción civil, además de asegurar un ambiente estanco, sin infiltraciones para poder proporcionar ambientes con temperaturas más suaves. En este sentido, el objetivo de este estudio fue evaluar si el uso de una manta de PVC impermeabilizante mejora el confort térmico en los edificios. Las pruebas se realizaron en laboratorio y en campo, evaluando la variación de temperatura en los lados opuestos de tejas con y sin revestimiento con manta de PVC impermeabilizante. En laboratorio, se evaluaron las temperaturas de la superficie bajo la incidencia de la luz de un reflector. En campo, la medición se realizó sobre la incidencia directa del sol. Los resultados permitieron concluir que la manta no solo actúa como agente impermeabilizante, pero también como reflector de la radiación solar, proporcionando una diferencia entre la temperatura externa e interna en la teja de hasta $20{ }^{\circ} \mathrm{C}$. El uso de mantas de 
PVC impermeables para la mejora térmica en los edificios es eficaz, provocando el reflejo de parte de la radiación solar incidente en la superficie de la cubierta del edificio, dificultando el paso del calor hacia el interior.

Palabras clave: Tejas; Manta de PVC; Evaluación térmica.

\section{Introdução}

Nos últimos anos tem ocorrido um aumento da temperatura global, influenciando diretamente a climatização de ambientes internos às edificações e, assim, ocorre uma busca crescente na construção civil por sistemas mais eficientes de estanqueidade térmica e consumo energético (Marinoski et al., 2010). Tem sido comum, estudos relacionados à questão do crescimento das cidades e a questão térmica relacionada ao ambiente e às habitações, bem como formas de como tratá-la, mitigando o calor gerado aos habitantes. Silva et al (2020), por exemplo, analisa a sensação térmica em um município cearense; Barbosa, Bezerra Neto e Caiana cujo trabalho visa analisar as ilhas de calor em centros urbanos, através do sensoriamento remoto. Tahara, Freire e Amorim (2013) avaliam o uso da metodologia Building Information Modeling (BIM) como ferramenta na busca pelo desempenho térmico em edificações, já na fase de projetação arquitetônica, visando obter melhores resultados às habitações. Estas e outras inúmeras publicações demonstram a preocupação atual em tratar da questão de conforto térmico em edificações. Deste modo, o setor de Arquitetura, Engenharia e Construção (AEC) vem analisando e estabelecendo critérios de comportamento térmico para materiais e sistemas que compõem os fechamentos e coberturas das edificações.

No Brasil, assim como na maioria dos países, uma edificação deve ser idealizada e projetada abrangendo os projetos executivos e arquitetônicos convencionais, além da ambientação desta no meio onde está inserida. A Norma Brasileira NBR 15.575 - Edificações Habitacionais (ABNT, 2013), mais conhecida como Norma de Desempenho, estabelece as diretrizes para que as edificações sejam bem construídas e proporcionem edificações condizentes com suas funções.

Segundo ASHRAE (2013), conforto térmico é o estado mental que expressa satisfação do homem com o ambiente que o circunda. A não satisfação com o ambiente pode ser causada pela sensação de desconforto, pelo calor ou pelo frio, quando o balanço térmico não é estável, ou seja, quando há diferenças entre o calor produzido pelo corpo e aquele perdido para o ambiente. Ainda, segundo a Norma de Desempenho (ABNT, 2013), em edificações construídas em desarmonia com o clima, até mesmo o uso de sistemas eletromecânicos de ventilação, refrigeração ou calefação podem ser insuficientes, gerando gastos energéticos desnecessários e perpetuando o problema de climatização do ambiente.

O desempenho térmico de uma edificação compreende a análise de informações e características a respeito dos produtos empregados na construção, sob as condições de solicitações ambientais, às quais a edificação estará sujeita durante sua vida útil (ABNT, 2013). Características como o local onde será inserida, a topografia e o clima são informações cruciais para prever quais soluções técnicas devem ser empregadas à construção. Ainda, os tipos de materiais, ou a combinação destes, devem ser avaliados, procurando obter o melhor resultado de conforto térmico para o usuário final da edificação (ABNT, 2013).

De acordo com Silveira, Marinoski e Lamberts (2012), a radiação solar é um dos fatores de maior contribuição para o ganho térmico em uma edificação, uma vez que as coberturas, normalmente proteções prioritárias contra incidência da radiação, são também a parte exposta à ação do calor. Dentre as causas relacionadas aos efeitos desta exposição nas coberturas, destaca-se a condição das superfícies de absorverem grande parte da radiação recebida. Assim, alguns sistemas de impermeabilização, como mantas, recebem em sua composição aditivos que as confere propriedades termo refletivas, colaborando com o isolamento térmico dos componentes impermeabilizados (Vittorino; Sato; Akutsu, 2003).

Deste modo, a configuração ideal para a cobertura de uma edificação deve atender às recomendações de Abreu, Abreu e Costa (2001), onde a superfície superior tenha alta refletividade às radiações solares e alta emissividade térmica e, em contra partida, sua superfície inferior tenha baixa refletividade solar e baixa emissividade térmica. Desta forma, as mantas, além da 
função impermeabilizante, podem proporcionar melhor conforto térmico e, consequentemente, promover uma redução no consumo energético que outrora seria realizado com climatização.

O sistema de impermeabilização com mantas sintéticas de PVC é um sistema flexível e pré-fabricado, composto por PVC com aditivos plastificantes e estabilizadores que formam uma resina, com a qual é elaborada a manta impermeabilizante. Entre as camadas da manta é adicionada uma malha estruturante de poliéster, garantindo uma melhor resistência aos esforços de tração e qualidade ao material (Cimino, 2002). Dentre os compostos que são utilizados em sua fabricação são empregados aditivos que protegem as mantas dos raios solares e raios ultravioletas, além de conferir propriedades antichamas, proteção antimicrorganismos, entre outras (Silva; Oliveira, 2006).

Analisando-se o cenário nacional e internacional, nota-se que diversas pesquisas vêm sendo realizadas sobre esse tema, ou seja, ambientação térmica através da reflexão dos raios solares, denotando a importância deste perante a urbanização e a necessidade de climatização térmica nas edificações (ABNT, 2013). Assim, diversos estudos abordam a pertinência de materiais de cobertura para a reflexão de raios UV e seu impacto no conforto térmico interno à edificação (Revel et al., 2014; De Masia; Ruggieroa; Vanolib, 2018; Antonaia et al., 2016; Ascione et al., 2018; Akbari; Levinson; Rainer, 2005; Synnefa; Saliari; Santamouris, 2012; Pisello et al., 2017), procurando apontar possíveis produtos que atendam à função desejada. Neste contexto, Coelho, Gomes e Dornelles (Coelho; Gomes; Dornelles, 2017) estudaram o desempenho térmico em telhas de fibrocimento (sem amianto), bem como a absortância solar, por meio de análises de temperatura superficial por termografia de infravermelho e outros ensaios específicos para avaliar o efeito do envelhecimento natural das peças, quando comparado a peças novas. Como resultado, este estudo concluiu que o envelhecimento natural das telhas de fibrocimento influencia seu desempenho térmico, uma vez que, por ficarem expostas às intempéries bem como aos agentes atmosféricos, tais como processo de carbonatação, eflorescência e microorganismos biológicos, ocorre uma alteração nos revestimentos superficiais das mesmas. Da mesma forma, Tokusumi e Foiato (Tokusumi; Foiato, 2019) também avaliam o desempenho térmico de telhas, especificamente termoacústicas, comparando com as de fibrocimento e cerâmicas, observando a perda média de calor quando comparando as superfícies externa e interna. Concluiu-se, ao final dos ensaios, que a telha termoacústica analisada apresentou desempenho térmico melhor do que as de fibrocimento e cerâmica, em relação à transferência de calor entre as superfícies externa e interna.

O objetivo deste estudo foi avaliar a variação de temperatura superficial em amostras de elementos de cobertura, sem revestimento ou revestidos com manta de impermeabilização à base de PVC, como produtos com propriedades termo refletivas. Procurou-se avaliar o comportamento térmico mediante a refletividade e redução do fluxo de calor entre as superfícies da cobertura, observando as diferenças entre a temperatura exposta e interna das superfícies estudadas. Tanto em ensaios em laboratório quanto em campo, verificou-se a efetividade do elemento impermeabilizante para impedir a troca de calor da parte exposta para a interna de telhas, demonstrando o ganho relativo ao conforto ambiental permitido pela manta de PVC aplicada à cobertura de uma edificação. Objetivou-se, assim, elucidar a efetividade desta solução para melhor ambientação térmica da edificação, para além de sua função primária, a impermeabilização.

\section{Metodologia}

Para a realização desta pesquisa contou-se com ensaios laboratoriais e de campo, objetivando avaliar as temperaturas superficiais em telhas de fibrocimento e aço galvanizado, comparando o comportamento destes elementos quando expostos ao calor, em estado natural e revestidos com manta PVC, utilizadas em impermeabilizações de coberturas ou outros elementos de construção. A seguir são apresentados os materiais e equipamentos utilizados, bem como os ensaios de laboratório e campo conduzidos para obtenção dos resultados. 


\subsection{Materiais utilizados}

Para a realização dos ensaios e estudos propostos neste artigo, os seguintes materiais foram utilizados: manta impermeabilizante de PVC, telhas de fibrocimento e de aço galvanizado, termopares, refletor de calor e câmera termográfica.

\section{a) Manta impermeabilizante de PVC}

A manta impermeabilizante escolhida para o desenvolvimento da pesquisa foi a manta auto adesiva TAI13-FP (PVC) da Ecotherm, de cor clara que, para cumprir sua função impermeabilizante, é colada na parte superior das telhas, evitando goteiras em coberturas.

\section{b) Telhas}

Para avaliar a variação de temperatura foram utilizados dois tipos de telhas: de fibrocimento e de aço galvanizado, encontradas no mercado e comumente utilizadas em coberturas de edificações.

As telhas de fibrocimento tinham dimensões: $1,0 \mathrm{~m}$ de comprimento, 0,7 $\mathrm{m}$ de largura e 4,0 $\mathrm{mm}$ de espessura. Uma telha foi revestida com a manta impermeabilizante de PVC e outra telha permaneceu em seu estado natural, sem manta (Figura 1).

Figura 1. Telhas de fibrocimento no estado natural (a) e revestida com manta impermeabilizante de PVC (b).

(a)

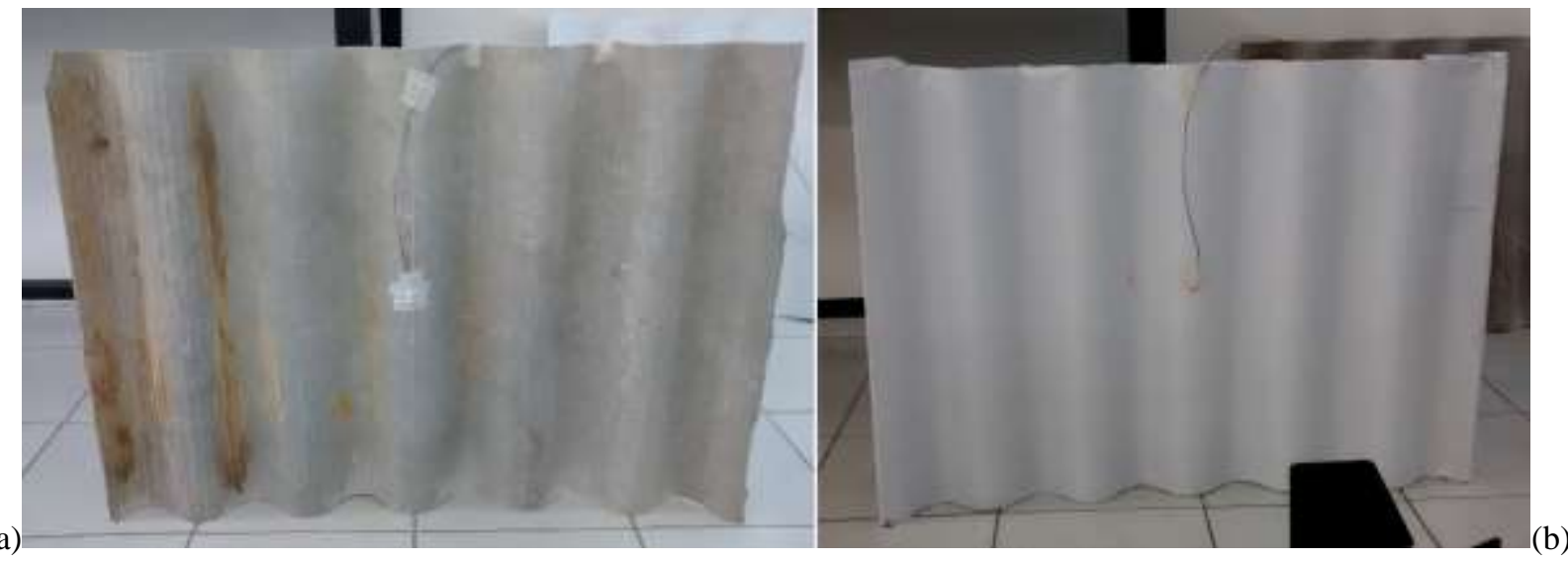

Fonte: Autores.

(b)

As telhas de aço galvanizado tinham dimensões: 0,90 m de comprimento, 0,6 m de largura e 4,3 mm de espessura. Uma telha foi revestida com a manta impermeabilizante de PVC e outra telha permaneceu em seu estado natural, sem manta (Figura 2).

\section{c) Fonte de calor}

No ensaio em laboratório foi utilizado um refletor KAISER videolight 6" de 1000W de potência, simulando a ação dos raios solares, aquecendo as telhas. A temperatura da cor da lâmpada halógena do refletor é de 3400K, sendo que a temperatura natural, emitida pela luz solar, é variável ao longo do dia, de mais "quente" a mais "fria". Sabe-se, porém, que, segundo Kucznynski e Muncinelli (2014), a luz branca natural do sol, sendo emitida ao meio dia, apresenta uma temperatura da cor de aproximadamente 5800k. 
Figura 2. Telhas de aço galvanizado no estado natural (a) e revestida com manta impermeabilizante de PVC (b).

(a)

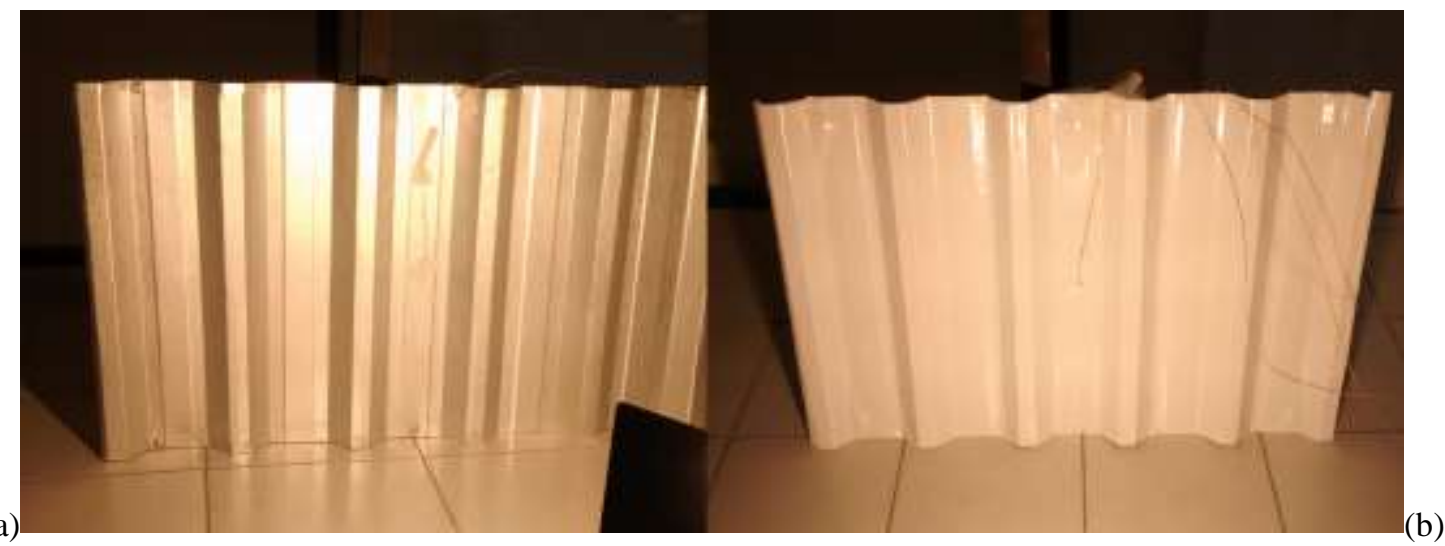

Fonte: Autores.

(b)

Em campo as telhas foram expostas ao sol, no período mais quente do dia.

\section{d) Medições da Temperatura}

As telhas foram submetidas a duas condições de medição de temperatura: uma em laboratório sob ação da fonte de calor e uma em campo, sob incidência solar.

Em laboratório, as medições de temperatura nas superfícies exposta e inferior das telhas submetidas à ação do calor foram feitas por meio dos termopares J1 e T2. O termopar J1 foi posicionado na superfície exposta ao calor e na superfície inferior foi utilizado um termopar tipo $\mathrm{T} 2$.

Nas medições em campo foi utilizada uma câmera termográfica FLIR modelo E6.

Os ensaios foram realizados na cidade de Guaratinguetá - SP, a qual está situada a 526 metros de altitude, com coordenadas geográficas: latitude: $22^{\circ} 48^{\prime} 58^{\prime \prime}$ Sul, longitude: $45^{\circ} 11^{\prime} 37^{\prime \prime}$ Oeste. A cidade apresenta um clima quente e temperado, sendo que a temperatura média anual na cidade é $20.0^{\circ} \mathrm{C}$, segundo Climate-Data (Climate-data.org, 2020).

\subsection{Preparação das amostras e procedimento experimental}

Em laboratório, nos pares de telhas, uma revestida com manta impermeabilizante de PVC e outra sem revestimento, foram colocados os termopares na parte central das 4 peças ensaiadas.

A Figura 3 mostra as telhas de aço galvanizado posicionadas, recebendo a incidência de calor do refletor.

Cada telha foi posicionada verticalmente diante do refletor a uma distância de um metro (Figura 3). Assim, o ensaio laboratorial teve início com uma telha à temperatura ambiente, recebendo incidência direta do refletor por 42 minutos. Com esse período pode-se observar, no laboratório, que após um período de 20 minutos de incidência de calor a temperatura se estabilizava. Isto serviu de referência para a duração do ensaio na área externa com a incidência da luz solar sobre as telhas.

Após o ensaio em laboratório, as mesmas telhas foram expostas em ambiente externo, em local aberto, com incidência direta dos raios de sol por um período de seis horas, considerando a maior incidência solar no intervalo (Figura 4). Neste período foram avaliadas as temperaturas nas superfícies expostas das telhas por meio da câmera termográfica.

Nos ensaios de laboratório foram avaliadas a temperatura superficial externa (TSe) e temperatura superficial interna (TSi), no período estabelecido para o estudo. Em campo foi avaliada somente a temperatura superficial externa, exposta aos raios solares. As telhas foram posicionadas sem ventilação na parte inferior com o objetivo de reproduzir a condição de exposição mais desfavorável. 
Figura 3. Posicionamento dos pares e início dos ensaios laboratoriais com termopares.

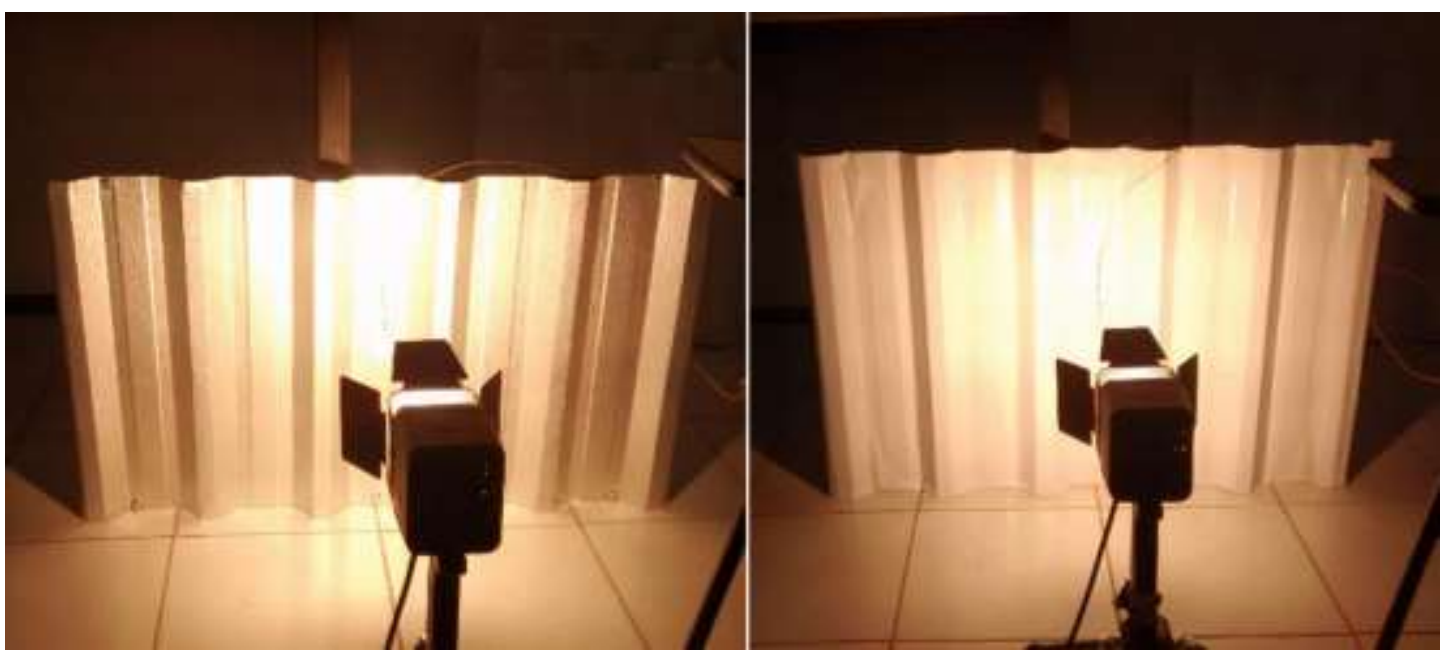

Fonte: Autores.

Figura 4. Posicionamento das telhas nos ensaios de campo.

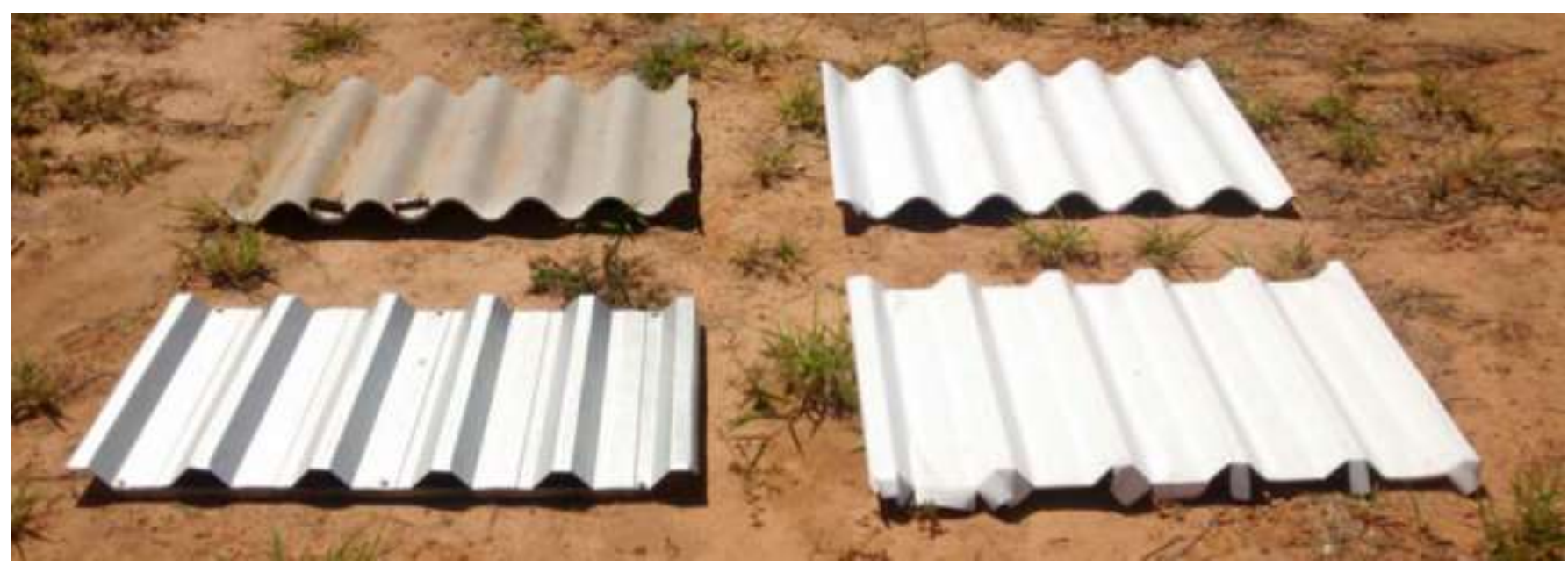

Fonte: Autores.

\section{Resultados e Discussão}

\subsection{Ensaios em laboratório}

A Figura 5 apresenta os resultados das telhas de aço galvanizado, com e sem revestimento de manta impermeabilizante de PVC, para temperaturas nas superfícies expostas e inferiores.

Nos resultados das telhas de aço galvanizado é possível observar, a partir das curvas da Figura 5, que as temperaturas ao longo do tempo das superfícies metálicas expostas (temperatura externa), com e sem a manta impermeabilizante de PVC, foram muito próximas (Figura 5a). No entanto, ao avaliar os resultados das temperaturas internas, sem e com o revestimento da manta impermeabilizante de PVC (Figura 5b), observa-se uma evolução de temperatura bem diferente, em que o revestimento proporcionou uma diminuição de temperatura significativa desde o início das medições.

A Tabela 1 apresenta os resultados das temperaturas máximas obtidas nestas telhas de aço galvanizado, bem como as variações de temperatura. 
Figura 5. Resultados da variação de temperatura nas superfícies exposta (a) e inferior (b) das telhas de aço galvanizado, sem e com manta impermeabilizante de PVC, sob ação da fonte de calor em laboratório.

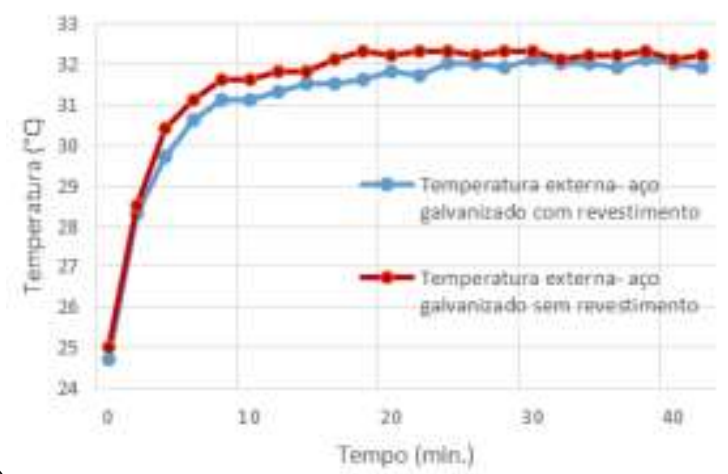

(a)

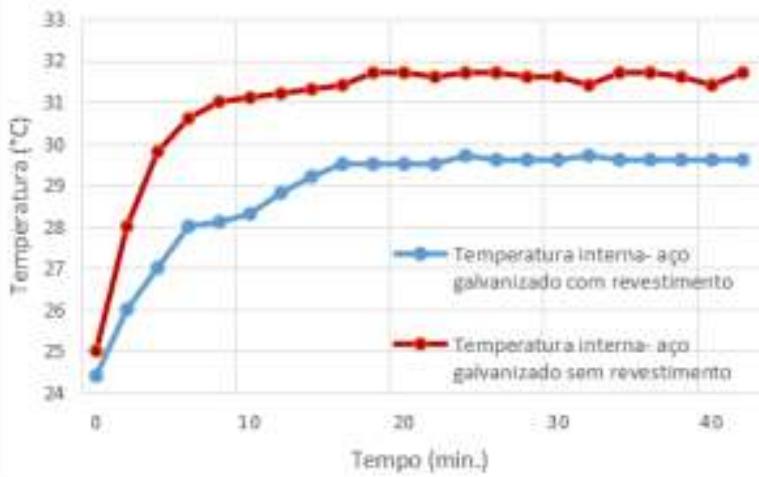

Fonte: Autores.

Tabela 1. Resultados das temperaturas no início e fim dos ensaios em laboratório das telhas de aço galvanizado.

\begin{tabular}{c|c|c|c|c|c|c}
\hline & \multicolumn{3}{|c|}{ sem manta PVC } & \multicolumn{3}{c}{ com manta PVC } \\
\hline Tempo de exposição (min) & $\mathbf{T S}_{\mathbf{e}}\left({ }^{\circ} \mathbf{C}\right)$ & $\mathbf{T S}_{\mathbf{i}}\left({ }^{\circ} \mathbf{C}\right)$ & $\Delta \mathbf{t}\left({ }^{\circ} \mathbf{C}\right)$ & $\mathbf{T S}_{\mathbf{e}}\left({ }^{\circ} \mathbf{C}\right)$ & $\mathbf{T S}_{\mathbf{i}}\left({ }^{\circ} \mathbf{C}\right)$ & $\Delta \mathbf{t}\left({ }^{\circ} \mathbf{C}\right)$ \\
\hline Início da medição & 25,0 & 25,0 & 0,0 & 24,7 & 24,4 & 0,3 \\
\hline Após 42 min & 32,3 & 31,7 & 0,6 & 32,1 & 29,7 & 2,4 \\
\hline $\boldsymbol{\Delta t}\left({ }^{\circ} \mathbf{C}\right)$ & 7,3 & 6,7 & - & 7,4 & 5,3 & - \\
\hline
\end{tabular}

Fonte: Autores.

A Figura 6 apresenta os resultados obtidos para as telhas de fibrocimento, sem e com revestimento de manta impermeabilizante de PVC, e a Tabela 2 apresenta os resultados das diferenças máximas de temperatura nas superfícies exposta e interna das telhas.

Os resultados de laboratório, apresentados na Figura 6, indicam que a manta impermeabilizante de PVC diminuiu a temperatura externa das telhas de fibrocimento $\left(1,9{ }^{\circ} \mathrm{C}\right)$. E a manta proporcionou uma diminuição de $40 \%$ (Tabela 2$)$ em relação à diferença de temperatura interna e externa sem manta $\left(7,6^{\circ} \mathrm{C}\right)$. No caso das telhas de fibrocimento, a refletividade e condução térmica da manta impermeabilizante de PVC auxiliam na redução do ganho e transmissão de calor (Michels, 2007; Bueno, 1994). 
Figura 6. Resultados da variação de temperatura nas superfícies externas (a) e internas (b) das telhas de fibrocimento sem e com revestimento.

(a)

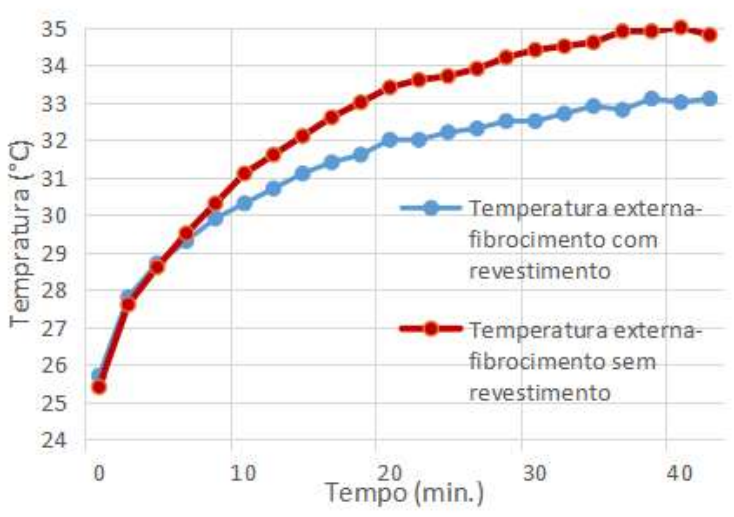

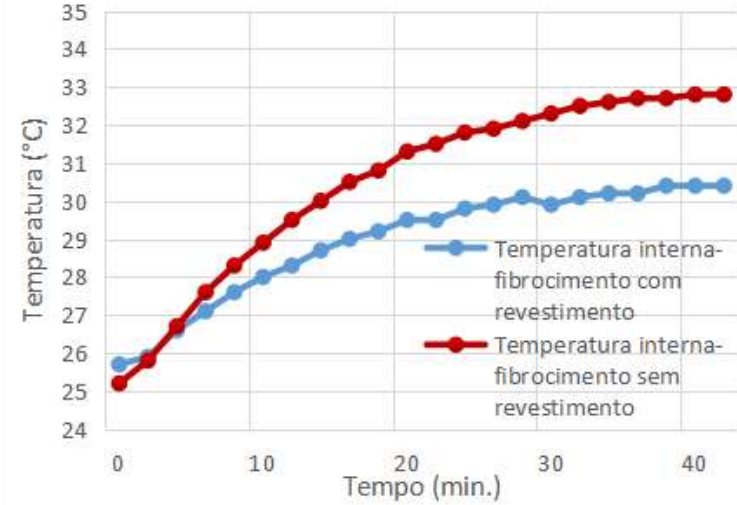

(b)

Fonte: Autores.

Tabela 2. Resultados da variação final de temperatura nas telhas de fibrocimento.

\begin{tabular}{c|c|c|c|c|c|c}
\hline & \multicolumn{3}{|c|}{ SEM manta pvc } & \multicolumn{3}{c}{ COm manta pvc } \\
\hline Tempo de exposição (min) & $\mathbf{T S}_{\mathbf{e}}\left({ }^{\circ} \mathbf{C}\right)$ & $\mathbf{T S}_{\mathbf{i}}\left({ }^{\circ} \mathbf{C}\right)$ & $\Delta \mathbf{t}\left({ }^{\circ} \mathbf{C}\right)$ & $\mathbf{T S}_{\mathbf{e}}\left({ }^{\circ} \mathbf{C}\right)$ & $\mathbf{T S}_{\mathbf{i}}\left({ }^{\circ} \mathbf{C}\right)$ & $\Delta \mathbf{t}\left({ }^{\circ} \mathbf{C}\right)$ \\
\hline Início da medição & 25,4 & 25,2 & 0,2 & 25,7 & 25,7 & 0,0 \\
\hline Após 42 min & 35,0 & 32,8 & 2,2 & 33,1 & 30,4 & 2,7 \\
\hline $\boldsymbol{\Delta t}\left({ }^{\circ} \mathbf{C}\right)$ & 9,6 & 7,6 & - & 7,4 & 4,7 & - \\
\hline
\end{tabular}

Fonte: Autores.

\subsection{Ensaios de campo}

A seguir são apresentados os resultados obtidos a partir do levantamento das temperaturas com as telhas expostas ao sol, realizados com a câmera termográfica. A Figura 7 apresenta os termogramas das telhas de fibrocimento, com (Figura 7a) e sem revestimento (Figura 7b), respectivamente. As temperaturas foram próximas a $65{ }^{\circ} \mathrm{C}$ para a telha sem revestimento e de $42{ }^{\circ} \mathrm{C}$ nas telhas com revestimento. Esta diferença observada pode ser justificada pelo fato de a superfície sem revestimento não possuir propriedades refletivas, que contribuem para a redução de ganho térmico provenientes da radiação solar (Michels, 2007; Bueno, 1994).

Figura 7. Resultado da termografia nas superfícies externas das de telhas de fibrocimento sob ação do sol, com (a) e sem (b) revestimento.
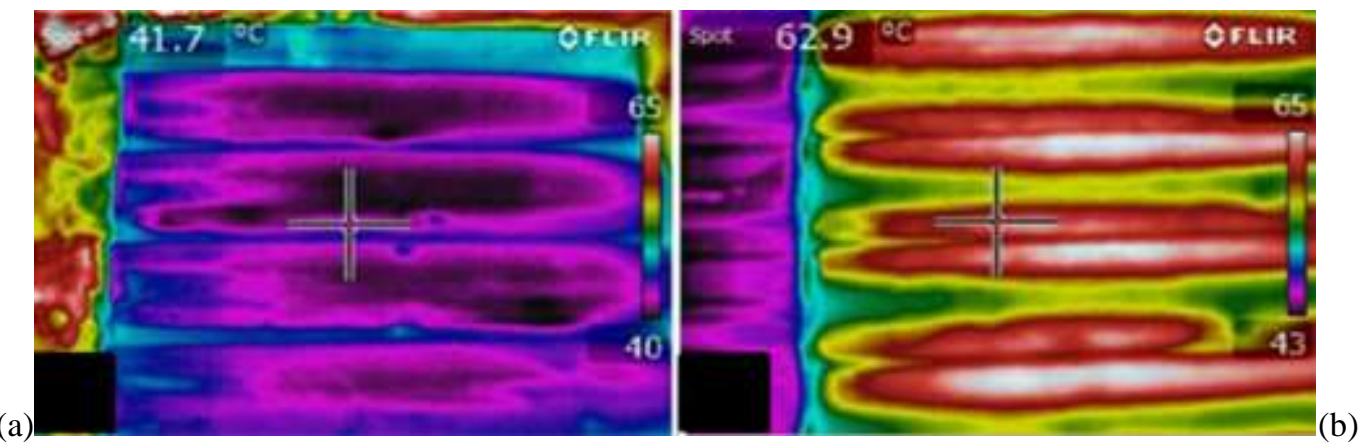

Fonte: Autores. 
Nas telhas de fibrocimento, notou-se uma alta redução da carga térmica na superfície da telha revestida com manta PVC de, aproximadamente, $20^{\circ} \mathrm{C}$. Como relatado, o ganho térmico da amostra com revestimento é retardado/barrado devido à superfície externa possuir características refletivas à radiação solar. Neste caso, observa-se que a manta impermeabilizante de PVC atribui à telha de fibrocimento uma propriedade termo-refletiva, que faz com que grande parte da radiação incidente seja refletida de volta para a atmosfera, diminuindo assim a absorção de radiação e, consequentemente, sua temperatura superficial (Michels, 2007; Bueno, 1994), como observado nos resultados de laboratório.

Esta reflexão de radiação que acarreta reduções da temperatura, também é em parte atribuída à cor da manta que, por ser branca, contribui de maneira mais efetiva na retransmissão da radiação, absorvendo apenas uma pequena parte desta radiação (Castro et al., 2003).

A Figura 8 apresenta as imagens termográficas das telhas de aço galvanizado, com e sem revestimento, submetidas à exposição solar. Pelo fato de a superfície ser metálica, houve uma variação da temperatura na superfície, que foi notada somente após a coleta dos dados. Esperava-se um valor superior da temperatura nas telhas metálicas sem revestimento; no entanto, foram inferiores aos valores obtidos pela telha de fibrocimento $\left(43,4{ }^{\circ} \mathrm{C}\right.$ contra $\left.62,9{ }^{\circ} \mathrm{C}\right)$ ). Por outro lado, as telhas com revestimento da manta impermeabilizante de PVC tiveram um desempenho muito bom $\left(41,8{ }^{\circ} \mathrm{C}\right)$, semelhante ao desempenho das telhas de fibrocimento $(41,7)$, indicativo de que a manta contribui para a diminuição da temperatura superficial e externa das telhas.

Figura 8. Termografias apresentando temperaturas superficiais em pares de telhas de aço galvanizado, com (a) e sem revestimento (b), respectivamente.
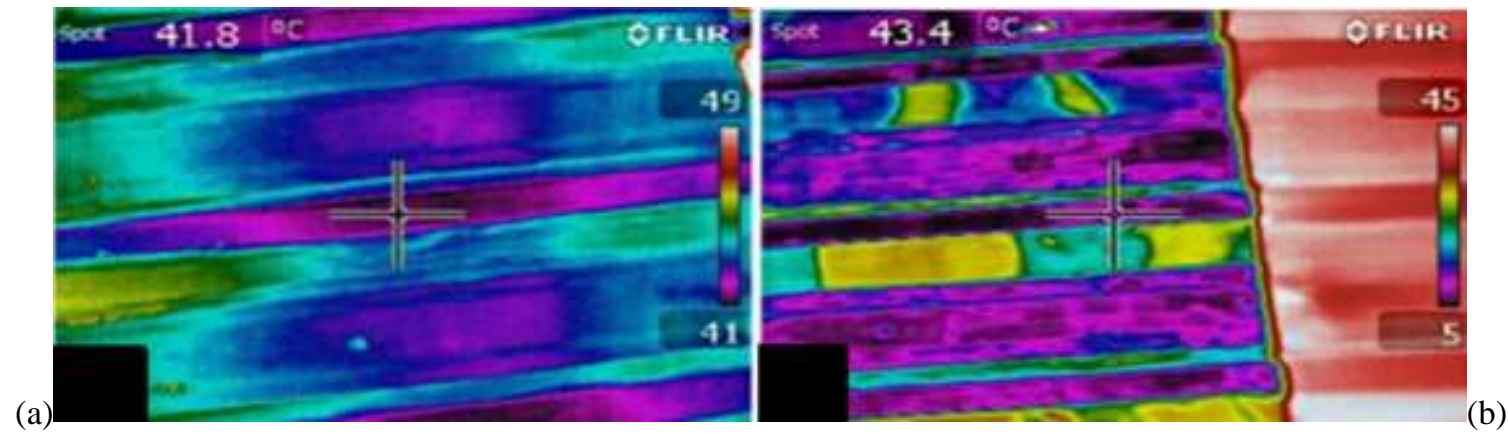

Fonte: Autores.

Os resultados obtidos neste estudo são confirmados por trabalhos correlatos, tratando, por exemplo, da avaliação de materiais aplicados para funções além daquela para as quais foram criados, ou estudando a troca de calor entre as superfícies de telhas comumente usadas em construções, discutidos a seguir.

O estudo de Tokusumi e Foiato (2019) avalia o comportamento térmico de telhas para temperaturas variando ente $0{ }^{\circ} \mathrm{C}$ e $40{ }^{\circ} \mathrm{C}$. A comparação foi realizada entre telhas termoacústicas, cerâmicas e fibrocimento, sem qualquer tratamento adicional, observando a variação entre as superfícies externas e internas. Observou-se, ao final do estudo, que as telhas de cerâmica e de fibrocimento, sem tratamento, não apresentaram comportamento favorável na análise térmica, com uma perda de calor médio entre as superfícies pouco significativa. Estes resultados indicam que mantas de proteção melhoram o conforto térmico, o que confirma os resultados observados neste estudo.

Pisello et al. (2017), como nesta pesquisa que avalia o uso de um material designado inicialmente para a função impermeabilização, apresenta uma membrana inovativa que é avaliada para a função de reflexão e ambientação térmica. O resultado deste estudo mostra os benefícios da aplicação de materiais deste tipo em diferentes pontos de uma edificação em termos de conforto térmico, principalmente no verão. 
Isto demonstra que produtos existentes podem ser adequados à função de reflexão, mas aponta que estudo aprofundado quanto ao envelhecimento do material e a redução de suas propriedades reflexivas deve ser avaliado em situação real de aplicação (De Masia; Ruggieroa; Vanolib, 2018; Ascione et al., 2018).

De Masia, Ruggieroa, Vanolib (2018) observam que apesar da telha de aço galvanizado possuir certa refletância inerente a sua constituição convencional, por possuir superfície lisa e cor de alumínio, sua cobertura com a manta impermeabilizante de PVC ainda oferece vantagem significativa, como observado também no estudo ora apresentado.

Synnefa, Saliari; Santamouris (2012) avaliaram as diferenças entre a temperatura externa e interna das superfícies, como as estudadas neste trabalho, encontrando temperaturas internas mais baixas que as externas, favorecendo o conforto térmico e diminuindo o consumo de energia elétrica, corroborando com os resultados obtidos neste trabalho.

\section{Conclusão}

O desenvolvimento do presente estudo possibilitou uma análise laboratorial da propriedade termo-isolante da manta impermeabilizante à base de PVC em coberturas, evidenciando sua efetividade no conforto térmico de edificações.

De modo geral, o revestimento sobre a telha atua como uma proteção refletiva que bloqueia a passagem de uma grande quantidade de ondas solares, provenientes da radiação incidente nas telhas.

Os ensaios realizados em laboratório demonstraram que o calor incidente sobre o revestimento da manta PVC obteve maior dificuldade para transitar da superfície externa (incidente) para a superfície interna das amostras, indicando a efetividade da manta impermeabilizante de PVC como um material auxiliar na diminuição da temperatura interna dos ambientes.

Os ensaios realizados em campo apresentaram uma diferença próxima a $20^{\circ} \mathrm{C}$ entre as temperaturas superficiais das amostras com e sem revestimento das telhas de fibrocimento. As telhas de aço galvanizado com revestimento de manta impermeabilizante tiveram o mesmo desempenho das telhas de fibrocimento. Esse resultado indica a efetividade e bom desempenho de mantas que não eram, a princípio, para esse fim.

Assim, os resultados permitem apurar que a utilização da manta sintética impermeabilizante de PVC como um revestimento auxiliar na melhoria térmica dos ambientes foi eficiente, uma vez que os experimentos realizados resultaram na redução das temperaturas superficiais e, principalmente, da temperatura superficial interna das amostras de telhas fibrocimento e aço galvanizado que receberam o revestimento.

Finalmente, conclui-se que o uso de mantas de impermeabilização para coberturas, quando claras e com outras características que favoreçam a reflexão dos raios solares, conferem à edificação muito mais do que se propõe, ou seja, garantir a estanqueidade dos elementos da construção, propiciando adicionalmente melhorias consideráveis ao conforto dos ambientes construídos e seus usuários.

\section{Referências}

ABNT, NBR 15.575 (2013). Desempenho de edificações habitacionais, Rio de Janeiro, 2013.

ABNT, NBR 9.575 (2010). Impermeabilização, Rio de Janeiro, 2010.

Abreu, P. G., Abreu, V. M. N., \& Costa, O. A. D, (2001). Avaliação de Coberturas de Cabanas de Maternidade em Sistema Intensivo de Suínos Criados ao Ar Livre (Siscal), no Verão. Revista Brasileira de Zootecnia, 30 (6), 1728-1734..

Antonaia, A., Ascione, F., Castaldo, A., D'angelo, A., De Mais, R. F., Ferrara, M., Vanoli D, G. P., \& Vitiello, G. (2016). Cool materials for reducing summer energy consumptions in Mediterranean climate: In-lab experiments and numerical analysis of a new coating based on acrylic paint. Applied Thermal Engineering, 102, 91-107.

Akbari, H., Levinson, R., \& Rainer, L. (2005). Monitoring the energy-use effects of cool roofs on California commercial buildings. Energy and Biuldings, 37, 1007-1016.

Ascione, F., De Mais, R. F., Santamouris, M., Ruggiero, S., \& Vanoli, G. P. (2018). Experimental and numerical evaluations on the energy penalty of reflective roofs during the heating season for Mediterranean climate. Energy, 144, 178-199. 
ASHRAE, Standard 55 (2013). Thermal Environmental Conditions for Human Occupancy, Estados Unidos, 2013.

Barboza, E. N., Bezerra Neto, F.C.; \& Caiana, C.R.A. (2020). Sensoriamento Remoto aplicado à análise do fenômeno de Ilhas de Calor Urbano na Cidade de Vitória, Espírito Santo. Research, Society and Development, 9 (6), 1-21.

Bueno, A. D. (1994). Transferência de Calor e Umidade em Telhas: Simulação e Análise Experimental. Dissertação (Mestrado em Engenharia Civil) Universidade Federal de Santa Catarina, Florianópolis.

Castro, A. P. A. S., Labaki, L. C., Caram, R. M., Basso, A., \& Fernandes, M. R. (2003). Medidas de refletância de cores de tintas através de análise espectral. Ambiente Construído, 3 (2), 69-76.

Cimino, R. (2002). Como Construir: Revestimento de Reservatório de Água com Manta Armada de PVC. Téchne, 62.

Climate-data.org. (2020). Clima: Guaratinguetá-SP. https://pt.climate-data.org/america-do-sul/brasil/sao-paulo/guaratingueta-3088/\#temperature-graph .

Coelho, T. da C. C.; Gomes, C. E. M.; \& Dornelles, K. A. (2017). Desempenho térmico e absortância solar de telhas de fibrocimento sem amianto submetidas a diferentes processos de envelhecimento natural. Ambiente Construído, 17 (1), 147-161.

De Masia,R. F., Ruggieroa, S., \& Vanolib, G. P. (2018). Acrylic white paint of industrial sector for cool roofing application: Experimental investigation of summer behavior and aging problem under Mediterranean climate. Solar Energy, 169, 468-487.

Kuczynski D. A, \& Muncinelli G. (2014). Estudo de comparação das características de desempenho técnico e financeiro da tecnologia led com as fluorescentes e incandescentes em ambiente residencial. Ágora: rev. divulg. cient. [Internet]. 19(1):149-73. http://www.periodicos.unc.br/index.php/agora/article/view/336

Marinoski, D. L., De Souza, G. T., Sangoi, J. M., \& Lamberts, R. (2010). Utilização de Imagens em Infravermelho para Análise Térmica de Componentes Construtivos. In: XIII Encontro Nacional de Tecnologia do Ambiente Construído, Canela.

Michels, C. (2007). Análise da transferência de calor em coberturas com barreiras radiantes. Dissertação (Mestrado em Engenharia Civil) - Universidade Federal de Santa Catarina, Florianópolis.

Pisello, A. L., Castaldo, V. L., Piselli, C., Fabiani, C., \& Cotana, F. (2017). Thermal performance of coupled cool roof and cool facçade: Experimental monitoring and analytical optimization procedure. Energy and Buildings, 157, 35-52.

Revel, G. M., Martarelli, M., Emiliani, M., Celotti, L., Nadalini, R., Ferrari, A., Hermanns, S., \& Beckers, E. (2014). Cool products for building envelope Part II: Experimental and numerical evaluation of thermal performances. Solar Energy, 105, 780-791.

Silva, D. O., \& Oliveira, P. S. F. (2006). Impermeabilização com mantas de PVC. Téchne, 111.

Silva, E. M., Barboza, E. N., Morais, J. M. P., Souza, J. H. A, \& Oliveira, B. B. (2020). Análise de sensação térmica no município de Barbalha, Ceará. Research, Society and Development, 9 (7), 1-21.

Silveira, R., Marinoski, D. L., \& Lamberts, R. (2012). Avaliação da absortância à radiação solar e temperatura superficial de telhas de fibrocimento utilizadas nas coberturas de edificações do campus da UFSC. In: XIV Encontro Nacional de Tecnologia do Ambiente Construído, Juiz de Fora.

Synnefa, A., Saliari, M., \& Santamouris, M. (2012). Experimental and numerical assessment of the impact of increased roof reflectance on a school building in Athens. Energy and Buildings, 55, 7-15.

Tahara, A., Freire, M. R., \& Amorim, A. L. (2013). Estudo da ferramenta Ecotect na avaliação do desempenho térmico no contexto BIM. In: III Simpósio Brasileiro de Qualidade do Projeto no Ambiente Construído; VI Encontro de Tecnologia de Informação e Comunicação na Construção, Campinas.

Tokusumi, A. T. G.; \& Foiato, M. (2019). Análise de desempenho termoacústico de telhas. Conhecimento Em Construção, 6, 35-48. 2019. https://portalperiodicos.unoesc.edu.br/conhecconstr/article/view/21833.

Vittorino, F., Sato, N. M. N., \& Akutsu, M. (2003). Desempenho térmico de isolantes refletivos e barreiras radiantes aplicados em coberturas. In: VII Encontro Nacional de Conforto no Ambiente Construído, Curitiba. 